\title{
Functionality of road safety devices - identification and analysis of factors
}

\author{
Lukasz Jeliński ${ }^{1,{ }^{*}}$, Kazimierz Jamroz ${ }^{1}$, Jan Jamroz ${ }^{1}$, and Marcin Antoniuk ${ }^{1}$ \\ ${ }^{1}$ Gdansk University of Technology, Faculty of Civil and Environmental Engineering, Gdansk, Poland
}

\begin{abstract}
Road safety devices are designed to protect road users from the risk of injury or death. The principal type of restraint is the safety barrier. Deployed on sites with the highest risk of run-off-road accidents, safety barriers are mostly found on bridges, flyovers, central reservations, and on road edges which have fixed obstacles next to them. If properly designed and installed, safety barriers just as other road safety devices, should meet a number of functional features. This report analyses factors which may deteriorate functionality, ways to prevent this from happening and the thresholds for loss of road safety device functionality.
\end{abstract}

\section{Introduction}

Run-off-road (ROR) crashes, is still of the unresolved road safety issues. The consequences of such event are secondary accidents ending with: turning the vehicle or hitting the vehicle at a facility near the road (tree, pole, ramp). ROR account for more than one third of all road users killed in road accidents in Poland. Road safety devices are a group of devices that reduce the probability and the effects of a vehicle ROR. Road safety devices in this article are: traffic safety equipment (road safety barriers, energy-saving equipment, crash cushions) and traffic layout devices (vertical marking, horizontal marking). These measures must meet the criteria of vitality and many functional properties such as, ,-safety, reliability, efficiency, effectiveness, preparedness, day and night visibility, etc.

\section{Defining the functionality of road safety devices}

The basic term that helps assess whether a device is fit for purpose is functionality. The functionality (practicality) of road safety devices means that they have to stay in operation 24 hours a day and 365 days a year. Continuity of operation ensures that road users are provided on an on-going basis with the right quality of parameters for communicating and receiving information, for driving a vehicle and with safety.

The functionality of road safety devices is managed by:

1. In the case of road traffic safety devices - maintaining a high level of preparedness (reliability); ensuring that the functionality stays strong if drivers behave the wrong way or vehicles break down (enforced driver behaviour, making sure the vehicle stays on the road, protection of road users' health and life, protection of objects and people on the road); monitoring the basic parameters of the devices (e.g. poor condition, loss of

* Corresponding author: lukjelin@pg.gda.pl 
technical parameters) through maintenance, exchange or use of more modern solutions, swift repairs of damage and breakdown.

2. In the case of traffic layout devices - ensuring a well-functioning traffic by making traffic layout devices clearly visible in day-time and night-time; monitoring the basic parameters (e.g. retro-reflective features) through treatment and exchange or application of more modern solutions, swift repairs.

The functionality of safety devices depends on the type and durability of the material they are made of [2], and the conditions in which the devices are deployed (weather, winter maintenance, occurrence of micro crashes by vehicles).

\section{Measures and requirements for safety barrier functionality}

The functionality of safety barriers is assessed primarily against the standard PN-EN 1317. It is an indispensable document used for developing safe road restraints. It sets out the criteria and methods for crash tests of road restraints, including safety barriers, before they can be used on public roads. While the standard does not specify the size, shape or material of safety barriers, it describes the operating classes of safety barriers by identifying their functionality features such as: containment level, deflection expressed with working width and crash intensity.

Eight most frequent functionality features are assigned functionality measures divided by road safety devices and road sections that have these devices.

Table 1. Total time from the first look until the target is passed and Time during which driver's gaze is fixed on target (ms) in 4 analysed situations [3].

\begin{tabular}{|c|c|c|}
\hline Approach & Individual & Societal \\
\hline Features of functionality: & Road safety device & Road section \\
\hline Safety & ASI, THIV, PHD & $\begin{array}{c}\text { societal and economic } \\
\text { consequences }\end{array}$ \\
\hline Reliability & Wm, VI, Dm & closure time, time lost \\
\hline Capacity & - & capacity \\
\hline $\begin{array}{c}\text { Maintain and redirect the } \\
\text { vehicle }\end{array}$ & $\begin{array}{c}\text { wheel position, displacement, } \\
\text { load, course of driving }\end{array}$ & closure time, time lost \\
\hline $\begin{array}{c}\text { Performance } \\
\text { degree, size of damage }\end{array}$ & congestion (traffic jams) \\
\hline Capacity to restore & restorability & closure time, time lost \\
\hline Economic effectiveness & $\begin{array}{c}\text { costs of construction, exchange, } \\
\text { removal }\end{array}$ & $\begin{array}{c}\text { costs of accident and time } \\
\text { lost }\end{array}$ \\
\hline
\end{tabular}

The resulting impact accelerations and decelerations are measured using: the Acceleration Severity Index (ASI), characterizing the intensity of the impact, and is regarded as the most important rate of impact on occupants; the theoretical head impact velocity (THIV), describes the theoretical speed of the head, colliding with an obstacle during an impact. It has to be less than $33 \mathrm{~km} / \mathrm{h}$; and the post-impact head deceleration (PHD) describes the head deceleration after an impact and has to be less than $20 \mathrm{~g}$ (acceleration of gravity). 
The dynamic deflection (Dm), the working width (Wm) and the vehicle intrusion (VI) allow a determination of the conditions for installation of each safety barrier and also to define the distances to be provided in front of obstacles.

\section{Methods for assessing the functionality of road safety devices}

\subsection{Studies of road safety device functionality}

US and Swedish research [3-7] shows the importance of repairing damaged safety barriers. Failure to do so may lead to loss of functionality. It is clear that a completely damaged safety barrier must be repaired. Safety barriers are frequently affected by minor damage such as shallow dents, the result of collisions at low speeds and small approach angles. Minor damages may also be caused by routine maintenance work, snow ploughing, mowing operations or variable weather. Regardless of the cause of damage, maintenance services must be able to identify those defects, which if untreated, may have fatal consequences. The authorities responsible for the road may be held liable for failure to keep the safety barriers operational. Clearly, there is a need for guidelines to help with assessing damage to safety barriers. It is important to ensure that road maintenance services have the capacity to identify what may seem as minor damage to road safety devices.

The research of recent years $[5,6]$ was primarily focused on identifying the criteria for assessing the degree of damage to steel safety barriers. A tool was to be developed to show the urgency of putting in a new safety barrier in place of a damaged one. The research methodology was based on a review of the literature and a survey of maintenance agencies to establish the methods they used for safety barrier repairs. The review of the literature looked primarily at available national guidelines for repairing safety barriers and guidelines followed by state road authorities. The guidelines of road agencies would usually have two components: (1) maintenance manuals that described the conditions and requirements for repairs, especially safety barrier repairs and (2) maintenance assessment criteria which are used to assess barrier functionality.

With the literature review as the basis, the NCHRP agency developed and sent 22 questions to road maintenance agencies. The questions were divided into five sections: (1) inventory of guardrail and median barriers, (2) repair policies, (3) non-crash related damage or deterioration, (4) notifications and repair responsibilities, (5) inspection policies and procedures.

The purpose of the barrier inventory section was to understand the types of barriers most used by specific road agencies. The repair policies section was intended to provide insight into what thresholds are currently used to determine barrier repair needs, how damaged sites are prioritized, timelines for repairs, documented cases of impacts into damaged barriers, and whether the agency would benefit from more quantitative barrier repair guidelines. The noncrash section looked at the occurrence of corrosion of steel elements, rotting of wooden elements and loss of tension in the case of lines. The notifications and repair responsibilities section was added to diagnose the procedures applied when repairs are diagnosed formally or informally and who is responsible for the repair. The final point in the survey covered inspection policies and procedures and was designed to collect information about types of inspections and how they are conducted and to understand what maintenance assessment methods are used.

To identify the criteria for assessing the degree of damage to steel safety barriers, crash tests and computer simulations were conducted using damaged barriers. The damages were to reflect a variety of damages normally encountered on the roads. The crash tests were 
conducted using a pendulum and car. The computer simulations were based on the finite element method in the programme LS-DYNA.

One of the tests analysed the effects of a missing or damaged post on barrier performance upon a crash. To that end a simulation was conducted using the finite element method in the programme LS-DYNA. The simulation was validated based on available literature data from previous crash tests. The simulation was designed to test how many posts can be removed while still keeping the operational performance of the barrier. The simulations were conducted for 1, 2 and 3 missing posts (Fig. 1) with the crashes conducted at two points: at the beginning of an unsupported span and mid-span where the missing post should be.

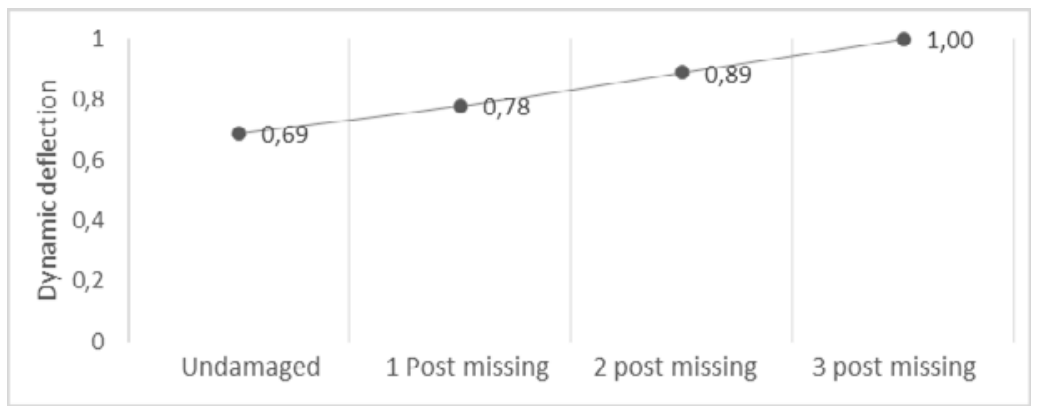

Fig. 1. Simulation results of the barrier crash where the post links into the guardrail.

Based on the results, the scientists concluded that even if only one post is missing/damaged, barrier functionality deteriorates significantly. While none of the vehicles in the simulation overturned, they exhibited significant instability. As a result, such damage was given a high repair priority.

\subsection{Guidelines for assessing the functionality of road safety devices}

Introduced in 2008, US guidelines [3] for the repairs of steel safety barriers are the US's mandatory document required by the FHWA (Federal Highway Administration). It is dedicated to road maintenance personnel and gives a comprehensive description of the importance and logistics of steel barrier repairs. The guidelines specify when safety barriers must be repaired, which barriers should be exchanged without any delay and classify barrier damage degrees. Damaged barriers are divided into three categories: (1) non-functional, (2) damaged but still functional, (3) functional with minor damage. Table 3 shows a diagram of the method for assessing functionality and damage classification.

\begin{tabular}{|c|c|c|c|c|}
\hline $\begin{array}{l}\text { Category of } \\
\text { functionality }\end{array}$ & Repair priority & Level of risk & Action & Damage \\
\hline (1) Non-functional & $\begin{array}{l}\text { High } \\
\text { crashing into the barrier may } \\
\text { lcad to uncxpected bchaviour of } \\
\text { vehicle and safety barrier }\end{array}$ & unacceptable & Immediate repair & - \\
\hline $\begin{array}{l}\text { (2) Damaged but } \\
\text { still functional }\end{array}$ & $\begin{array}{l}\text { Medium } \\
\text { less likely to cause consequences } \\
\text { expected for high risk }\end{array}$ & Tolerable & $\begin{array}{c}\text { Repair at a later } \\
\text { date }\end{array}$ & \\
\hline $\begin{array}{l}\text { (3) Functional with } \\
\text { minor damage }\end{array}$ & $\begin{array}{l}\text { Low } \\
\text { no significant difference between } \\
\text { the damaged and a new } \\
\text { undamaged barrier }\end{array}$ & Acceptable & $\begin{array}{l}\text { Repair as part of } \\
\text { routine barrier } \\
\text { maintenance }\end{array}$ & \\
\hline
\end{tabular}

Fig. 3. Method for functionality assessment in the US [3]. 
US guidelines [3] determine the category of safety barrier functionality based on quantitative data. Category 1 of functionality - barrier is no longer reasonably functional the rail element is separated (no barrier continuity), partly torn or the rail height is less than $610 \mathrm{~mm}$. In addition, category 1 is when (1) there are three or more broken, bent, or separated posts and the amount out of alignment is less than $305 \mathrm{~mm}$ or (2) if the amount out of alignment is greater than $30 \mathrm{~cm}$ regardless of post damage. Category 2 of functionality barrier should function adequately under a majority of impacts - if the guardrail is out of alignment not more than $152 \mathrm{~mm}$ and not more than 1-2 posts or when the guardrail is out of alignment not more than $305 \mathrm{~mm}$ and not more than 2 damaged posts. Category of functionality 3 - the barrier meets functionality parameters and no replacement is necessary - applies if the posts have no damage and the guardrail is out of alignment by less than 152 $\mathrm{mm}$.

As prescribed by the FHWA guidelines, the type of damage is decisive for whether the device must be repaired or not. The report recommends repairs to Category 1 damage as soon as possible, depending on the hazard it causes for other users. In the case of Category 2 and 3 , because the risk is lower, repairs can be made later or as part of routine maintenance.

\section{Concept of a functionality assessment method}

Today, when maintenance checks are conducted, it is not possible to inspect road safety devices for all the functional features on site. Additional on-site, lab and simulation tests are required. Following from preliminary analyses, a method is proposed for assessing the functionality of road safety devices using a qualitative and quantitative assessment. The qualitative method for assessing road safety device functionality involves a visual check of the condition of the device. The operational performance of a device is established by checking the guardrail for being out of alignment, system integrity, corrosion or damage to protective layers. The quantitative method for functionality assessment should be divided into simplified and detailed. The simplified quantitative method uses the simplest tools for measuring the degree of damage such as depth of deflection, angle of post deflection, etc. The detailed method supports very accurate measurements such as a change in the thickness of anti-corrosion surfaces. There are not many specialist tools available in Poland and worldwide capable of clearly establishing whether a device is functional and to what extent. In this case the quantitative method is justified only if supported with guidelines for assessing the deterioration of road safety devices.

The guidelines should include a classification of damage by type of device and a clear definition of acceptable amounts out of alignment. Equipped with such tools, maintenance services are able to decide on the priority of damaged devices.

Building on the studies and guidelines for assessing safety barrier functionality, work can begin to conduct new research and develop national guidelines for road safety device maintenance. Proposed by the authors, the concept of a method for assessing the functionality of road safety devices involves five stages of tests: 1) Identify the most frequent damage, 2) Assess the functionality of devices using the damage database, 3) Assess the risk involved in each identified hazard, 4) Assess risk acceptability, and 5) Select actions and priorities for repairs. 


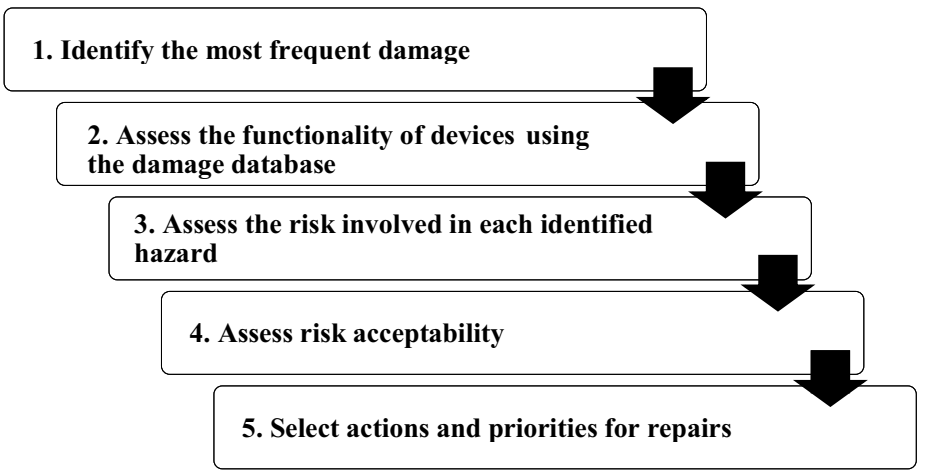

Fig. 2. The concept of a method for assessing the functionality of road safety devices.

Work on the concept of risk assessment is part of a research project for the NCBiR (National Centre for Research and Development) and the GDDKiA (General Directorate for National Roads and Motorways): Project RID 3B "The effects of time and operational conditions on the durability and functionality of road safety elements".

\section{Conclusions}

Road safety barriers must meet a number of functional features such as: safety, reliability, operational performance, effectiveness, preparedness, etc. Research is needed to tackle unsolved problems, i.e. lack of methods for assessing the effects of safety barrier type, durability and operational conditions on the functionality of the types of safety barriers, lack of methods for selecting the thresholds for assessing the features (functions) of the devices. The most important function of road safety devices is to protect road and roadside users from the risk of injury or death. While there is extensive independent research into the effects of selected factors on road safety device functionality [8], a comprehensive approach is still in short supply.

\section{Acknowledgements}

Research conducted under project implemented within RID programme, funded by the Polish National Centre for Research and Development and the General Directorate for National Roads and Motorways in Poland, for the years 2016-2019.

\section{References}

1. Journal of Laws of the Republic of Poland, Annex to nru 220, pos. 2181 of 23 December 2003, Detailed technical conditions for road signs, signals, traffic safety equipment and conditions for locating them on the road (2003)

2. NCHRP Report 711, Guidance for the selection, use, and maintenance of cable barrier systems (Washington DC, 2012)

3. FHWA, W-Beam Guardrail Repair: A Guide for Highway and Street Maintenance Personnel (U.S. Department of Transportation, 2008)

4. AASHTO, Maintenance Manual for Roadways and Bridges, 4th Edition (American Association of State Highway and Transportation Officials, Washington, 2007)

5. D. Gabauer, H.C. Gabler, Review of Current Damage-Level Criteria for Longitudinal 
Barrier Repair, Transp. Res. Rec. 702 pp. 1-17 (2008)

6. H.C. Gabler, D.J. Gabauer, C.E. Hampton, Criteria for Restoration of Longitudinal Barriers, NCHRP Report 656, t. 22, no. 646 (2010)

7. G. Fredriksson, H.G. Holmen, The ageing of safety barriers . Functional limits for safety barriers that deviate from the nominal in height and / or perpendicular position, (2013)

8. K. Jamroz, M. Budzyński, W. Kustra, L. Michalski, S. Gaca, Tools for road infrastructure safety management - Polish experiences, in: Transp. Res. Procedia, pp. 730-739 (2014). doi:10.1016/j.trpro.2014.10.052 